\title{
Correction: Complementary therapies for labour and birth study: a randomised controlled trial of antenatal integrative medicine for pain management in labour
}

Levett KM, Smith CA, Bensoussan A, et al. Complementary therapies for labour and birth study: a randomised controlled trial of antenatal integrative medicine for pain management and labour. BMJ Open 2016;6:e010691 doi:10.1136/bmjopen2015-010691.

There are several amendments to this article:

Reference 23 should be Betts D. Acupressure techniques for use during childbirth and pregnancy. http://acupuncture.rhizome.net.nz (accessed 2015 2005).

The sentence: Acupressure, ${ }^{22}{ }^{24}$ which uses six main points for use during labour selected from a previously published protocol. ${ }^{23}$ These focus on hormone release for labour progression, augmentation of contractions, pain relief, nausea and positioning of baby.

Should read: Acupressure, ${ }^{22} 24$ which uses six main points for use during labour selected from a previously published protocol. ${ }^{23}$ The participants were given DVDs of the acupressure protocol ${ }^{23}$ to take home for practice. These focus on hormone release for labour progression, augmentation of contractions, pain relief, nausea and positioning of baby.

The sentence: The LAS contains 29 questions with a seven-point Likert scale ranging from ' $1=$ almost always', to ' $7=$ =rarely'. Therefore, scores could theoretically range from 29, indicating the highest control possible, to a high score of 203 indicating the lowest agency possible.

Should read: The LAS contains 29 questions with a seven-point Likert scale ranging from ' $1=$ almost always', to ' $7=$ =rarely'. Therefore, scores could theoretically range from 29, indicating the lowest control possible, to a high score of 203 indicating the highest agency possible.

The acknowledgements have been corrected to include: Dr Debra Betts provided the acupressure protocol for labour and birth and can be accessed at this address: https://acupuncture.rhizome.net.nz/). Dr Debra Betts (debra.betts@rhizome.net.nz) and Tom Kennedy (tzkennedy@hotmail.com) provided the DVD for the study participants. None were directly involved in this study.

Reference 1 in the supplementary data has been corrected to:

Reference 1: Betts D. Acupressure techniques for use during childbirth and pregnancy. http://acupuncture.rhizome.net.nz (accessed 2015 2005).

Open Access This is an Open Access article distributed in accordance with the Creative Commons Attribution Non Commercial (CC BY-NC 4.0) license, which permits others to distribute, remix, adapt, build upon this work noncommercially, and license their derivative works on different terms, provided the original work is properly cited and the use is non-commercial. See: http://creativecommons.org/licenses/by-nc/4.0/

BMJ Open 2016;6:e010691corr1. doi:10.1136/bmjopen-2015-010691corr1 